\title{
Clinical adjacent-segment pathology after central corpectomy for cervical spondylotic myelopathy: incidence and risk factors
}

\author{
Aditya Vedantam, MD, ${ }^{1}$ and Vedantam Rajshekhar, $\mathrm{MCh}^{2}$ \\ 1Department of Neurosurgery, Baylor College of Medicine, Houston, Texas; and 2Department of Neurological Sciences, Christian \\ Medical College, Vellore, India
}

OBJECTIVE The goal of this study was to investigate the prevalence and risk factors of clinical adjacent-segment pathology (CASP) following central corpectomy for cervical spondylotic myelopathy (CSM) or ossification of the posterior longitudinal ligament (OPLL).

METHODS The authors reviewed 353 cases involving patients operated on by a single surgeon with a minimum 12-month follow-up after central corpectomy for CSM or OPLL between 1995 and 2007. Patients with symptoms consistent with CASP at follow-up were selected for the study. The authors analyzed the prevalence and risk factors for CASP after central corpectomy for CSM/OPLL.

RESULTS Fourteen patients ( 13 male, 1 female; mean age $46.9 \pm 7.7$ years) were diagnosed with symptoms of CASP (3.9\% of 353 patients) at follow-up. The mean interval between the initial surgery and presentation with symptoms of CASP was $95.6 \pm 54.1$ months (range 40-213 months). Preoperative Nurick grades ranged from 2 to 5 (mean $3.5 \pm 1.2$ ), and the Nurick grades at follow-up ranged from 1 to 5 (mean $3.0 \pm 1.3, p=0.27$ ). Twelve patients had myelopathic symptoms and 2 had radiculopathy at follow-up. Patients with poorer preoperative Nurick grades had a higher risk for development of CASP (HR 2.6 [95\% Cl 1.2-5.3], $p=0.01$ ).

CONCLUSIONS In the present study, CASP was seen in $3.9 \%$ of patients following central corpectomy for CSM/OPLL. The risk of CASP after central corpectomy for CSM/OPLL was higher in patients with poorer preoperative Nurick grades. http://thejns.org/doi/abs/10.3171/2016.2.FOCUS1626

KEY WORDS adjacent-segment disease; cervical corpectomy; cervical spondylotic myelopathy; subaxial cervical spine

\section{$\mathrm{L}$} ONG-TERM results following anterior decompression of the cervical spine for cervical spondylotic myelopathy (CSM) have been largely satisfactory. ${ }^{2,3,11,30}$ However, a small subset of these patients present with new neurological symptoms or delayed functional deterioration at follow-up. Delayed neurological symptoms after anterior decompression for CSM have been largely attributed to adjacent-segment disease, more accurately described as clinical adjacent-segment pathology (CASP).$^{8,10,18,31}$ CASP refers to new clinical symptoms that correlate with radiographic changes at levels adjacent to previous spine fusion and is distinct from radiographic adjacent-segment pathology, which refers to radiographic changes seen at levels adjacent to previous spine fusion without concordant clinical findings. ${ }^{18}$

Previous studies have described the incidence of CASP after anterior cervical discectomy and fusion, $, 8,10,12,14$ with a mean rate estimated at $1.6 \%-4.2 \%$ per year after surgery. ${ }^{18}$ Data on the incidence of CASP after central corpectomy for CSM are limited, with only $17.3 \%$ (71) of the patients in the series from Hilibrand et al. ${ }^{8}$ undergoing central corpectomy. Central corpectomy has been shown to accelerate radiographic adjacent-segment pathology ${ }_{15}^{15}$ and it is expected that the unique biomechanical stresses associated with this procedure would affect the incidence of CASP in this population.

ABBREVIATIONS CASP = clinical adjacent-segment pathology; CSM = cervical spondylotic myelopathy; OPLL = ossification of the posterior longitudinal ligament. SUBMITTED January 19, 2016. ACCEPTED February 26, 2016.

INCLUDE WHEN CITING DOI: 10.3171/2016.2.FOCUS1626. 
In this report, we studied the prevalence of CASP in patients with a minimum of 12 months of follow-up after uninstrumented central corpectomy for CSM or ossification of the posterior longitudinal ligament (OPLL). We also evaluated risk factors that predispose these patients to CASP.

\section{Methods \\ Patient Population}

The present study is a retrospective review of prospectively collected data. At the Christian Medical College, Vellore, we maintain a prospective clinical database of all patients who undergo uninstrumented central corpectomy. Four hundred sixty-eight patients underwent central corpectomy performed by a single surgeon (V.R.) for CSM/ OPLL between 1995 and 2007 in our surgical unit. Of these, 353 patients $(75.4 \%)$ were followed up postoperatively for 12 months or more, and cases involving patients who presented with new or recurrent neurological symptoms attributable to CASP at follow-up were reviewed in the present study. CASP was defined as the presence of clinical symptoms (radiculopathy or myelopathy) that correlated with radiographic changes at levels adjacent to the previous fusion. ${ }^{18}$ Radiological changes were observed on MR images of the cervical spine obtained at follow-up showing cord or root compression at a level adjacent to the fused levels. OPLL was diagnosed on radiographs and MR images preoperatively, but all patients with diagnosed OPLL in this study were patients in whom the finding of OPLL was confirmed intraoperatively.

\section{Operative Procedure}

All patients underwent central corpectomy with autologous iliac bone or fibular grafting. The surgical procedure has been described previously ${ }^{16,26,28}$ and has produced favorable results on long-term evaluation. ${ }^{16,23,24} \mathrm{In}$ brief, the surgical procedure was as follows. Patients were positioned supine with Gardner-Wells skull traction and a rolled sheet under the shoulders. A skin crease incision was performed and neck dissection was used to reach the vertebral bodies. After the vertebral levels were confirmed with an intraoperative radiograph, a central corpectomy $(14-16 \mathrm{~mm})$ was performed. The posterior longitudinal ligament was either excised or "floated off." Autologous iliac bone graft was used for 1- and 2-level corpectomies, and fibular grafts were used for 3-level corpectomies. The graft was fitted into mortices created at the superior and inferior vertebral endplates, with the help of skull traction. An immediate postoperative radiograph was obtained to confirm graft position. Patients were walking with a hard cervical collar in the immediate postoperative period, and the collar was worn for 6 months postoperatively.

At follow-up, all patients underwent a neurological examination and Nurick grading, and radiographs and an MRI study of the cervical spine were obtained as indicated. Cervical spine curvature was measured using the method described by Batzdorf and Batzdorff. ${ }^{1}$ Loss of lordosis was confirmed when spines that had been lordotic preoperatively were noted to be straight or kyphotic at follow-up. Cervical fusion was confirmed by evidence of bony trabeculae bridging the fusion site on postoperative radiographs at a minimum of 1 year after surgery.

\section{Statistical Analysis}

Demographic and clinical data were analyzed using descriptive statistics. The Student t-test was used for subgroup analysis. To identify risk factors for new or recurrent symptomatic neurological dysfunction, a Cox regression model based on the duration of follow-up was created using preoperative variables such as age, sex, preoperative Nurick grade, duration of symptoms, number of vertebral levels, diabetes, and presence of OPLL. Means are reported with standard deviations. IBM SPSS version 20.0 (IBM Corp.) was used to analyze the data, and statistical significance was set at $\mathrm{p}<0.05$ (see Table 2).

\section{Results}

In the cohort of 353 patients (mean age $47.8 \pm 9.5$ years, 93.5\% male), the mean duration of symptoms before surgery was $21.2 \pm 30.8$ months. Single-level corpectomy was performed in 113 patients (32\%). Two hundred forty patients (68\%) underwent multilevel corpectomy (2-level in 229 cases; 3-level in 11), and OPLL was present in 109 patients $(30.9 \%)$. The median duration of follow-up for the cohort of 353 patients was 47 months (range 12-213 months). Follow-up imaging was available for 336 of these patients and yielded a fusion rate of $88 \%$, with fusion confirmed by evidence of bony trabeculae bridging the fusion site on postoperative radiographs. Major operative complications recorded for the entire cohort of 468 patients included recurrent laryngeal nerve injury $(0.4 \%), \mathrm{C}-5$ palsy $(1.3 \%)$, CSF leak (4.2\%), graft extrusion (1.9\%), and cervical wound infections (1.5\%). Graft donor site infections were seen in $1.9 \%$.

Fourteen patients (13 male, 1 female; mean age 46.9 \pm 7.7 years) were diagnosed with symptoms of CASP at follow-up (Table 1). OPLL was present in 8 patients. The mean duration of follow-up for these patients was $95.6 \pm$ 54.1 months (range 40-213 months). Preoperative Nurick grades ranged from 2 to 5 (mean $3.5 \pm 1.2$ ), and the Nurick grades at follow-up ranged from 1 to 5 (mean $3.0 \pm 1.3$, $\mathrm{p}=0.27$ paired-sample t-test). Twelve patients had myelopathic symptoms, characterized by lower limb tightness and worsening gait. Two patients had radiculopathic symptoms at follow-up.

\section{Imaging}

Of the 14 patients with CASP, 11 had prolapsed intervertebral discs at the adjacent segment. In 7 patients $(50 \%)$, spondylotic changes were seen inferior to the fused segments (Figs. 1 and 2), and in the other 7 patients, changes were noted superior to the fused segments (Fig. 3). Radiological features of neural compression seen at the adjacent segment at follow-up were not visualized prior to the fusion surgery. No patient with CASP had graftrelated complications such as pseudarthrosis or nonunion. Inadequate decompression of the cord at the operated site was not seen in any patient who had a cervical spine MRI study performed at follow-up. Spine curvature was lordotic in 11 patients $(78.5 \%)$ preoperatively and 6 patients 
TABLE 1. Summary of clinical and demographic characteristics of 14 patients with CASP following central corpectomy for CSM/OPLL

\begin{tabular}{|c|c|c|c|c|c|c|c|c|}
\hline $\begin{array}{l}\text { Case } \\
\text { No. }\end{array}$ & $\begin{array}{l}\text { Pt Age } \\
\text { (yrs), Sex }\end{array}$ & $\begin{array}{l}\text { Preop Nurick } \\
\text { Grade }\end{array}$ & Surgery & $\begin{array}{l}\text { Follow-Up } \\
\text { Nurick Grade }\end{array}$ & $\begin{array}{c}\text { Time (mos) to } \\
\text { Presentation w/ CASP }\end{array}$ & $\begin{array}{l}\text { CASP } \\
\text { Sx }\end{array}$ & $\begin{array}{c}\text { MRI } \\
\text { Features }\end{array}$ & Management \\
\hline $1^{*}$ & $52, \mathrm{M}$ & 5 & $\begin{array}{l}\text { C-6 \& C3-4 } \\
\text { discectomy }\end{array}$ & 4 & 50 & Myelop & $\begin{array}{l}\text { C4-5 disc herniation } \\
\text { w/ canal stenosis }\end{array}$ & Laminectomy \\
\hline 2 & $45, M$ & 2 & C-5 \& C-6 CC & 3 & 184 & Myelop & C3-4 disc herniation & Advised surgery \\
\hline 3 & $50, M$ & 4 & C-5 CC & 3 & 40 & Myelop & C6-7 disc herniation & Laminectomy \\
\hline 4 & $58, \mathrm{M}$ & 3 & C-4 CC & 5 & 108 & Myelop & C5-6 canal stenosis & $\begin{array}{l}\text { C-6 \& inferior C-5 } \\
\text { corpectomy \& iliac } \\
\text { bone grafting }\end{array}$ \\
\hline 5 & $60, \mathrm{~F}$ & 2 & C-5 CC & 5 & 29 & Myelop & C6-7 disc herniation & Laminectomy \\
\hline 6 & $30, \mathrm{M}$ & 2 & C-5 CC & 1 & 146 & Myelop & C6-7 disc herniation & $\begin{array}{l}\text { C6-7 discectomy \& } \\
\text { fusion }\end{array}$ \\
\hline 7 & $47, M$ & 5 & C-5 \& C-6 CC & 2 & 108 & Radiculop & C3-5 canal stenosis & $\begin{array}{l}\text { C3-4 \& C-5 hemilami- } \\
\text { nectomy }\end{array}$ \\
\hline 8 & $48, M$ & 4 & C-4 \& C-5 CC & 1 & 59 & Radiculop & C6-7 disc herniation & Advised surgery \\
\hline 9 & $48, M$ & 5 & C-4 \& C-5 CC & 4 & 86 & Myelop & C6-7 disc herniation & C6-7 discectomy \\
\hline 10 & $52, \mathrm{M}$ & 4 & C-4 \& C-5 CC & 4 & 46 & Myelop & C-6 canal stenosis & C3-6 laminectomy \\
\hline 11 & $42, \mathrm{M}$ & 5 & C-5 \& C-6 CC & 4 & 85 & Myelop & C3-4 disc herniation & C3-4 discectomy \\
\hline 12 & $42, \mathrm{M}$ & 3 & C-5 \& C-6 CC & 2 & 53 & Myelop & C3-4 disc herniation & C3-4 discectomy \\
\hline 13 & $45, M$ & 3 & C-4 \& C-5 CC & 2 & 114 & Myelop & C6-7 disc herniation & $\begin{array}{l}\text { Surgery not performed } \\
\text { due to cardiac } \\
\text { comorbidities }\end{array}$ \\
\hline 14 & $38, M$ & 2 & C-5 \& C-6 CC & 2 & 213 & Myelop & C3-4 disc herniation & C3-4 discectomy \\
\hline
\end{tabular}

$\mathrm{CC}=$ central corpectomy; myelop = myelopathy; $\mathrm{pt}=$ patient radiculop = radiculopathy; $\mathrm{Sx}=$ symptoms .

* This patient had OPLL.

postoperatively (42.8\%). Loss of lordosis was noted in 5 patients (35.7\%).

\section{Management of CASP}

Imaging findings and management of patients with
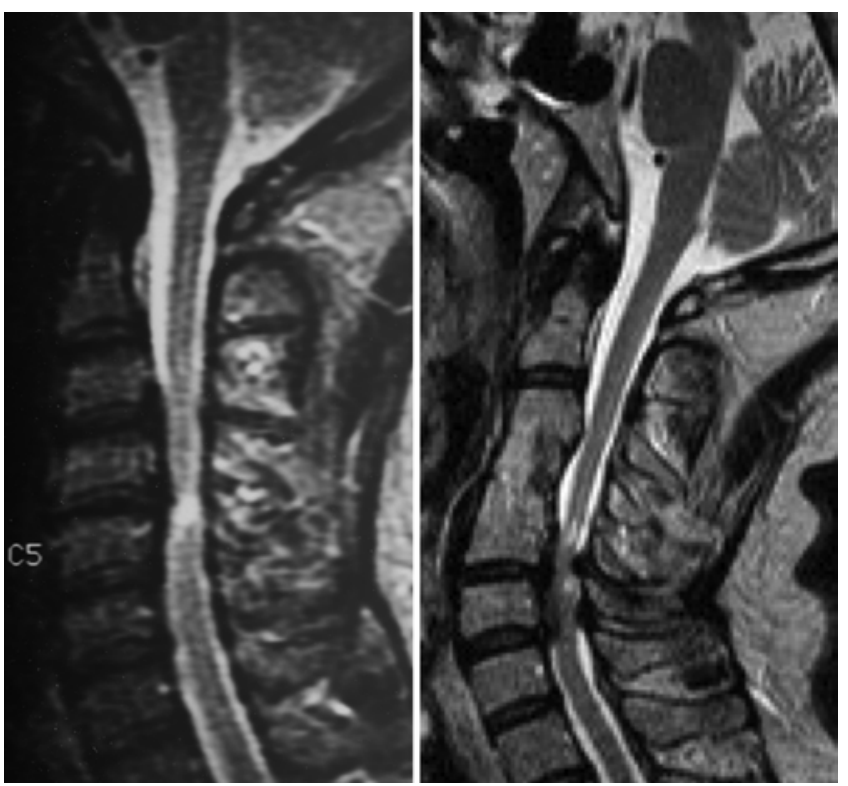

FIG. 1. Case 4. Sagittal T2-weighted MR images of the cervical spine obtained preoperatively (left) and 108 months after C-4 corpectomy (right). The follow-up image shows cord compression at the inferior adjacent segment.
CASP are described in Table 1. All patients were advised to undergo surgery for CASP. Three patients did not undergo surgery; 2 of these patients refused surgery, and 1 patient had considerable cardiac comorbidities that precluded surgery. Anterior cervical decompression for CASP was performed in 6 patients, and posterior decompression was performed in 5 .

\section{Risk Factors for CASP}

A worse preoperative Nurick grade was associated
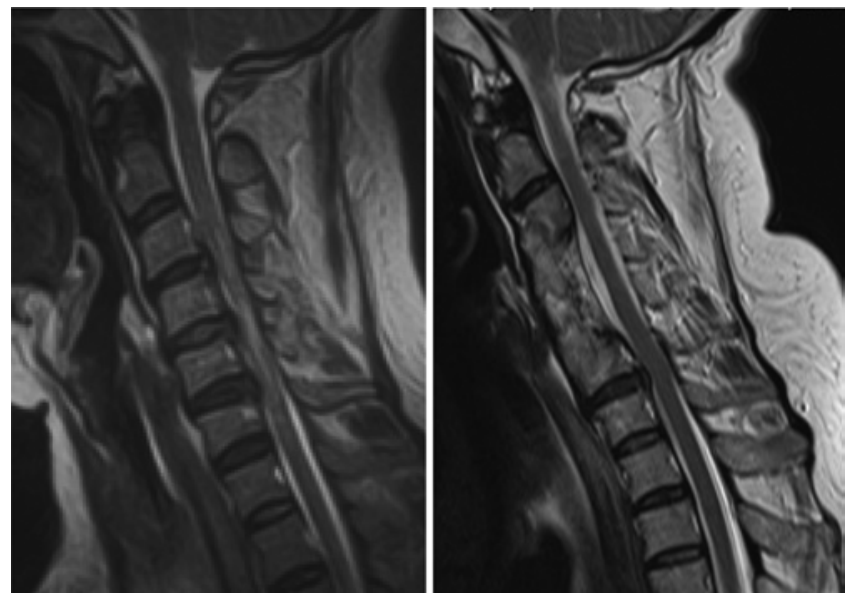

FIG. 2. Case 8. Sagittal T2-weighted MR images obtained preoperatively (left) and 59 months after C4-5 corpectomy (right) for CSM due to multilevel cord compression. The follow-up image shows disc herniation at the inferior adjacent segment (C6-7). 


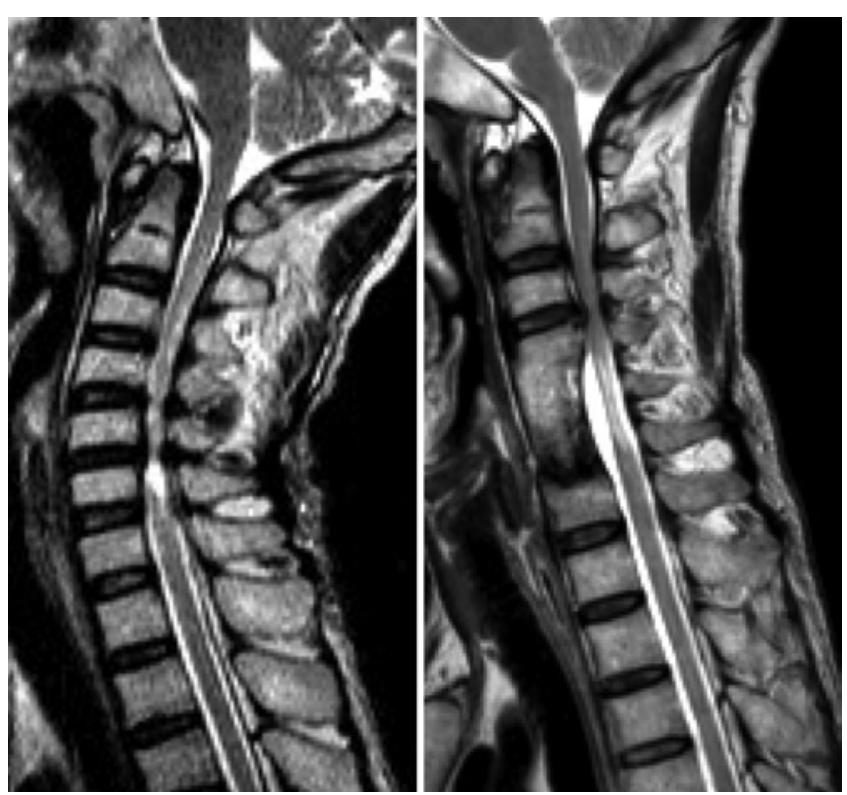

FIG. 3. Case 11. Sagittal T2-weighted MR images obtained preoperatively (left) and at follow-up (right), 85 months after C5-6 corpectomy for multilevel cord compression. The preoperative image shows cord compression at the C4-5 and C5-6 disc levels and cord signal change at the C-6 level. The follow-up image was obtained when the patient presented with myelopathic symptoms and shows cord compression at the superior adjacent segment (C3-4).

with an increased risk of CASP after central corpectomy in our series $(p=0.01)$. The duration of symptoms, presence of diabetes, and number of levels treated were not significantly associated with the CASP at follow-up. A Kaplan-Meier curve for the proportion of patients without CASP at follow-up is shown in Fig. 4. The estimated cumulative proportion of patients with CASP at 5 years was $3 \%$ and at 10 years was $14 \%$.

\section{Discussion}

The present study shows the prevalence of CASP after central corpectomy to be $3.9 \%$ in 353 patients who underwent central corpectomy for CSM/OPLL. The majority of the patients with CASP had myelopathic symptoms. Preoperative Nurick grade was independently associated with an increased risk of CASP after central corpectomy for CSM/OPLL.

Our study focused on patients undergoing central corpectomy, which is known to produce increased biomechanical stresses on the adjacent segments, ${ }^{9}$ as well as reduced cervical lordosis and segmental height, ${ }^{19,21}$ as compared with anterior cervical discectomy and fusion. The range of motion of adjacent segments after central corpectomy changes significantly after surgery, particularly at the inferior adjacent segment. ${ }^{28}$ While the removal of intervertebral discs to facilitate strut grafting can lower the risk of adjacent-segment pathology, the risk of CASP increases if fusion is adjacent to but excludes the C5-6 or C6-7 disc spaces. ${ }^{18}$ In the present series, the majority of our patients with CASP had levels adjacent to C5-6 or C6-7 fused.

Hilibrand et al. ${ }^{8}$ reported that $55(14.7 \%)$ of 374 patients

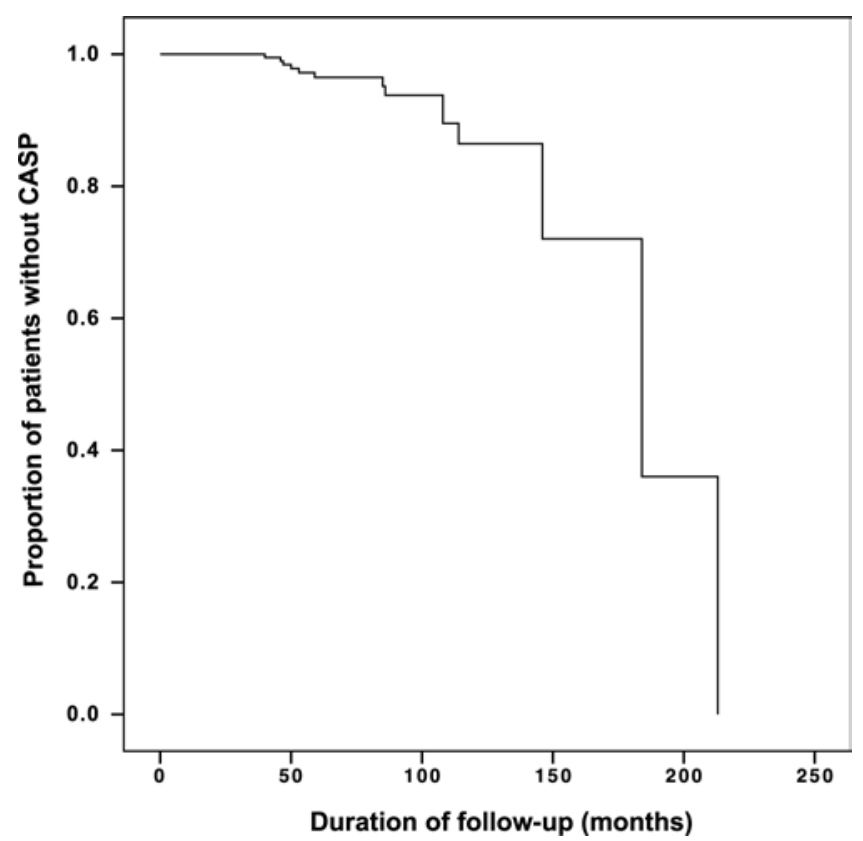

FIG. 4. Kaplan-Meier curve showing the proportion of patients without CASP at follow-up in a cohort of 353 patients undergoing central corpectomy for CSM/OPLL.

developed CASP and 27 (7.2\%) of these patients underwent a second surgery for CASP. Emery et al. ${ }^{3}$ showed that among 106 patients followed up for a minimum of 2 years after undergoing anterior cervical decompression, 9 patients $(8.5 \%)$ developed CASP and 5 patients $(4.7 \%)$ developed delayed recurrent myelopathy. Other authors have reported CASP requiring surgery in $9 \%-14 \%$ of cases at 5 or more years after follow-up. ${ }^{2,6} \mathrm{~A}$ systematic review of studies on the development of CASP after cervical fusion surgery reported a mean rate of reoperation for CASP of $0.8 \%$ per year and estimated the mean rate at $1.6 \%-4.2 \%$ per year. ${ }^{18} \mathrm{Wu}$ et al. ${ }^{29}$ showed a similar rate of reoperation for CASP after anterior cervical discectomy and fusion in a large nationwide database study. The prevalence of CASP after central corpectomy in our study was lower (14 of 353 patients, $3.9 \%$ ) than that reported by Hilibrand et al. ${ }^{8}$ and closer to the rate reported by Emery et al. ${ }^{3}$

A number of factors can affect the long-term outcome

TABLE 2. Cox regression model to identify risk factors for CASP after central corpectomy for CSM/OPLL

\begin{tabular}{lccc}
\hline \multicolumn{1}{c}{ Covariate } & $\mathrm{HR}$ & $95 \% \mathrm{Cl}$ for HR & $\mathrm{p} \mathrm{Value}$ \\
\hline Age & 1.0 & $0.9-1.1$ & 0.58 \\
\hline Sex & 0.2 & $0.02-2.2$ & 0.19 \\
\hline Duration of Sx & 1.0 & $0.9-1.03$ & 0.57 \\
\hline Preop Nurick grade & 2.6 & $1.2-5.3$ & $0.01^{*}$ \\
\hline No. of vertebral levels treated $\dagger$ & 1.3 & $0.2-7.1$ & 0.76 \\
\hline Diabetes mellitus $\neq$ & 0.0 & - & 0.99 \\
\hline OPLL & 0.9 & $0.2-3.4$ & 0.82 \\
\hline
\end{tabular}

$\mathrm{HR}=$ hazard ratio; $-=$ not applicable.

* Statistically significant $(p<0.05)$.

† Categorical variable: single-level versus multilevel fusion.

‡ Data available for 334 patients. 
following decompressive surgery for CSM. Previous authors have shown that male sex, age $15-59$ years, ${ }^{29}$ preoperative disc protrusion at the adjacent segment on MRI, ${ }^{10}$ and osteopenia predispose to CASP. In the present study, we found that the risk of CASP increased with poorer preoperative Nurick grades. In previous studies, we have shown that patients with preoperative Nurick Grade 4 or 5 do experience improvement after surgery ${ }^{23}$ but have poorer intermediate outcomes (3 years). ${ }^{27}$ In our series, a single grade increase in the preoperative Nurick grade more than doubled the risk of CASP. The natural history of disease has been shown to contribute to adjacent-segment degeneration. ${ }^{8}$ Patients with worse neurological function have been shown to have more severe spondylotic changes and cord compression. ${ }^{20,22}$ It is likely that these patients are more prone to accelerated progression of spondylotic changes at the adjacent segment as they age, contributing to increased incidence of CASP. Few authors have described the incidence of CASP after instrumented central corpectomy for CSM. Lau et al. ${ }^{17}$ showed that $1(6.3 \%)$ of 16 patients developed CASP after 2-level instrumented corpectomy and fusion for CSM at a mean follow-up duration of 32.1 months. Our incidence of CASP requiring surgery was close to that reported by Gao et al. ${ }^{5}$ (4.8\% in 145 patients after a mean follow-up period of 102.1 months). Although there are biomechanical differences in range of motion between instrumented and uninstrumented models, ${ }^{4,13}$ no study has compared the risks of CASP between instrumented and uninstrumented central corpectomy for CSM/OPLL. There is limited evidence that sagittal imbalance increases the risk of radiological adjacent-segment pathology, and there are no data for its impact on CASP; ${ }^{7}$ however, our analysis could not evaluate this variable further.

In our series, the number of levels fused did not predict CASP postoperatively. Hilibrand et al.$^{8}$ showed that single-level fusions were associated with an increased incidence of adjacent-segment degeneration. It is likely that early spondylotic changes at the adjacent level that were not addressed at the primary surgery may rapidly progress due to increased mobility at the adjacent level after corpectomy and fusion. ${ }^{15,28}$ Some authors have suggested including adjacent segments showing minor degeneration in the initial fusion, ${ }^{6,8}$ but increasing the number of surgically treated levels is associated with its own complications. ${ }^{2}, 25$ Cervical corpectomy and fusion as compared with anterior discectomy and fusion (the predominant surgery in the study by Hilibrand et al. ${ }^{8}$ ) involves removal of disc material at 2 levels, and this extensive decompression likely reduces the risk of adjacent-segment degeneration irrespective of the number of levels operated.

\section{Features of This Study}

Our report is unique in studying the causes of CASP following a uniform surgical procedure, central corpectomy performed by a single surgeon, in a large cohort of patients. The use of the mJOA scale (modified Japanese Orthopaedic Association scale) might have enabled us to better quantify new or recurrent neurological symptoms. The evaluation of cervical curvature and preoperative adjacent disc degeneration as an independent risk factor for CASP was not possible since these data were not available for the entire cohort. Few patients may have had subsequent follow-up at a center other than ours, and these data were not available to us. Importantly, this study adds data to the limited literature available on neurological deterioration after central corpectomy for CSM/OPLL, with the focus on clinically relevant adjacent-segment degeneration.

\section{Conclusions}

In the present study, the prevalence of CASP following central corpectomy for CSM was 3.9\%. Patients with poorer preoperative Nurick grades had an increased risk of CASP after central corpectomy for CSM/OPLL.

\section{Acknowledgments}

We thank Dr. L. Jeyaseelan of the Department of Biostatistics at Christian Medical College in Vellore for his assistance with the statistical analysis.

\section{References}

1. Batzdorf U, Batzdorff A: Analysis of cervical spine curvature in patients with cervical spondylosis. Neurosurgery 22:827-836, 1988

2. Bohlman HH, Emery SE, Goodfellow DB, Jones PK: Robinson anterior cervical discectomy and arthrodesis for cervical radiculopathy. Long-term follow-up of one hundred and twenty-two patients. J Bone Joint Surg Am 75:1298-1307, 1993

3. Emery SE, Bohlman HH, Bolesta MJ, Jones PK: Anterior cervical decompression and arthrodesis for the treatment of cervical spondylotic myelopathy. Two to seventeen-year follow-up. J Bone Joint Surg Am 80:941-951, 1998

4. Galler RM, Dogan S, Fifield MS, Bozkus H, Chamberlain $\mathrm{RH}$, Sonntag VK, et al: Biomechanical comparison of instrumented and uninstrumented multilevel cervical discectomy versus corpectomy. Spine (Phila Pa 1976) 32:1220-1226, 2007

5. Gao R, Yang L, Chen H, Liu Y, Liang L, Yuan W: Long term results of anterior corpectomy and fusion for cervical spondylotic myelopathy. PLoS One 7:e34811, 2012

6. Gore DR, Sepic SB: Anterior cervical fusion for degenerated or protruded discs. A review of one hundred forty-six patients. Spine (Phila Pa 1976) 9:667-671, 1984

7. Hansen MA, Kim HJ, Van Alstyne EM, Skelly AC, Fehlings MG: Does postsurgical cervical deformity affect the risk of cervical adjacent segment pathology? A systematic review. Spine (Phila Pa 1976) 37 (22 Suppl):S75-S84, 2012

8. Hilibrand AS, Carlson GD, Palumbo MA, Jones PK, Bohlman HH: Radiculopathy and myelopathy at segments adjacent to the site of a previous anterior cervical arthrodesis. J Bone Joint Surg Am 81:519-528, 1999

9. Hussain M, Nassr A, Natarajan RN, An HS, Andersson GB: Relationship between biomechanical changes at adjacent segments and number of fused bone grafts in multilevel cervical fusions: a finite element investigation. J Neurosurg Spine 20:22-29, 2014

10. Ishihara H, Kanamori M, Kawaguchi Y, Nakamura H, Kimura T: Adjacent segment disease after anterior cervical interbody fusion. Spine J 4:624-628, 2004

11. Kadoya S, Iizuka H, Nakamura T: Long-term outcome for surgically treated cervical spondylotic radiculopathy and myelopathy. Neurol Med Chir (Tokyo) 43:228-241, 2003

12. Katsuura A, Hukuda S, Saruhashi Y, Mori K: Kyphotic malalignment after anterior cervical fusion is one of the factors promoting the degenerative process in adjacent intervertebral levels. Eur Spine J 10:320-324, 2001 
13. Kirkpatrick JS, Levy JA, Carillo J, Moeini SR: Reconstruction after multilevel corpectomy in the cervical spine. A sagittal plane biomechanical study. Spine (Phila Pa 1976) 24:1186-1191, 1999

14. Komura S, Miyamoto K, Hosoe H, Iinuma N, Shimizu K: Lower incidence of adjacent segment degeneration after anterior cervical fusion found with those fusing C5-6 and C6-7 than those leaving C5-6 or C6-7 as an adjacent level. J Spinal Disord Tech 25:23-29, 2012

15. Kulkarni V, Rajshekhar V, Raghuram L: Accelerated spondylotic changes adjacent to the fused segment following central cervical corpectomy: magnetic resonance imaging study evidence. J Neurosurg 100 (1 Suppl Spine):2-6, 2004

16. Kumar GS, Rajshekhar V: Acute graft extrusion following central corpectomy in patients with cervical spondylotic myelopathy and ossified posterior longitudinal ligament. J Clin Neurosci 16:373-377, 2009

17. Lau D, Chou D, Mummaneni PV: Two-level corpectomy versus three-level discectomy for cervical spondylotic myelopathy: a comparison of perioperative, radiographic, and clinical outcomes. J Neurosurg Spine 23:280-289, 2015

18. Lawrence BD, Hilibrand AS, Brodt ED, Dettori JR, Brodke DS: Predicting the risk of adjacent segment pathology in the cervical spine: a systematic review. Spine (Phila Pa 1976) 37 (22 Suppl):S52-S64, 2012

19. Lin Q, Zhou X, Wang X, Cao P, Tsai N, Yuan W: A comparison of anterior cervical discectomy and corpectomy in patients with multilevel cervical spondylotic myelopathy. Eur Spine J 21:474-481, 2012

20. Ogino H, Tada K, Okada K, Yonenobu K, Yamamoto T, Ono $\mathrm{K}$, et al: Canal diameter, anteroposterior compression ratio, and spondylotic myelopathy of the cervical spine. Spine (Phila Pa 1976) 8:1-15, 1983

21. Oh MC, Zhang HY, Park JY, Kim KS: Two-level anterior cervical discectomy versus one-level corpectomy in cervical spondylotic myelopathy. Spine (Phila Pa 1976) 34:692-696, 2009

22. Penning L, Wilmink JT, van Woerden HH, Knol E: CT myelographic findings in degenerative disorders of the cervical spine: clinical significance. AJR Am J Roentgenol 146:793-801, 1986

23. Rajshekhar V, Kumar GS: Functional outcome after central corpectomy in poor-grade patients with cervical spondylotic myelopathy or ossified posterior longitudinal ligament. Neurosurgery 56:1279-1285, 2005

24. Rajshekhar V, Muliyil J: Patient perceived outcome after central corpectomy for cervical spondylotic myelopathy. Surg Neurol 68:185-191, 2007

25. Riew KD, Hilibrand AS, Palumbo MA, Bohlman HH: Anterior cervical corpectomy in patients previously managed with a laminectomy: short-term complications. J Bone Joint Surg Am 81:950-957, 1999

26. Thakar S, Vedantam A, Rajshekhar V: Correlation between change in graft height and change in segmental angle following central corpectomy for cervical spondylotic myelopathy. J Neurosurg Spine 9:158-166, 2008

27. Vedantam A, Jonathan A, Rajshekhar V: Association of magnetic resonance imaging signal changes and outcome prediction after surgery for cervical spondylotic myelopathy. J Neurosurg Spine 15:660-666, 2011

28. Vedantam A, Revanappa KK, Rajshekhar V: Changes in the range of motion of the cervical spine and adjacent segments at $\geq 24$ months after uninstrumented corpectomy for cervical spondylotic myelopathy. Acta Neurochir (Wien) 153:9951001, 2011

29. Wu JC, Liu L, Wen-Cheng H, Chen YC, Ko CC, Wu CL, et al: The incidence of adjacent segment disease requiring surgery after anterior cervical diskectomy and fusion: estimation using an 11-year comprehensive nationwide database in Taiwan. Neurosurgery 70:594-601, 2012

30. Yamamoto I, Ikeda A, Shibuya N, Tsugane R, Sato O: Clinical long-term results of anterior discectomy without interbody fusion for cervical disc disease. Spine (Phila Pa 1976) 16:272-279, 1991

31. Yonenobu K, Hosono N, Iwasaki M, Asano M, Ono K: Neurologic complications of surgery for cervical compression myelopathy. Spine (Phila Pa 1976) 16:1277-1282, 1991

\section{Disclosures}

The authors report no conflict of interest concerning the materials or methods used in this study or the findings specified in this paper.

\section{Author Contributions}

Conception and design: Rajshekhar. Acquisition of data: both authors. Analysis and interpretation of data: both authors. Drafting the article: Vedantam. Critically revising the article: both authors. Reviewed submitted version of manuscript: both authors. Approved the final version of the manuscript on behalf of both authors: Rajshekhar. Statistical analysis: Vedantam. Administrative/technical/material support: Rajshekhar. Study supervision: Rajshekhar.

\section{Supplemental Information \\ Previous Presentations}

Parts of this manuscript were presented as an abstract at the annual meeting of the Congress of Neurological Surgeons, October 6-12, 2012, in Chicago, Illinois.

\section{Correspondence}

Vedantam Rajshekhar, Department of Neurological Sciences, Christian Medical College, Vellore 632 004, Tamil Nadu, India. email: rajshekhar@cmcvellore.ac.in. 